\title{
Testing Link of Climatic Factors and Air Pollution with COVID-19 amid the Second Wave in India
}

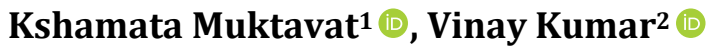 \\ ${ }^{1}$ Department of Applied Sciences and Humanities, Inderprastha Engineering College, Ghaziabad, India \\ ${ }^{2}$ Department of Environmental Engineering, Texas A\&M University, Kingsville, TX, USA \\ Email: kshamata.muktavat@ipec.org.in,vinay.kumar@tamuk.edu
}

How to cite this paper: Muktavat, K. and Kumar, V. (2021) Testing Link of Climatic Factors and Air Pollution with COVID-19 amid the Second Wave in India. Journal of Environmental Protection, 12, 1069-1085. https://doi.org/10.4236/jep.2021.1212063

Received: October 21, 2021

Accepted: December 11, 2021

Published: December 14, 2021

Copyright $\odot 2021$ by author(s) and Scientific Research Publishing Inc. This work is licensed under the Creative Commons Attribution International License (CC BY 4.0).

http://creativecommons.org/licenses/by/4.0/

\begin{abstract}
Several recent works indicated the association of climatic factors and air pollution with the spread of coronavirus disease-2019 (COVID-19, total daily confirmed deaths and new cases). Nonetheless, the impact of climatic and environmental conditions concerning virus spread and demise, yet not been solved. Present research work focuses on the spread of COVID-19 over five distinct states/territories of India; those have pretty different climatic conditions and the air quality index. The Kendall rank correlation and Spearman rank correlation tests at 95\% significance were used from 3 Jan-15 May 15, 2021 (132 days), including April 2021, a month of sharp rise COVID-19 second wave. For all the regions, a significant positive correlation of temperature $(>0.6)$ and a significant negative correlation of humidity $(<-0.5)$ is found with COVID-19 except for Kerala (insignificant and weak relationship). However, in the case of wind speed, a lower correlation is found everywhere except over Andhra Pradesh ( $>0.5)$. For all the states, a significant and consistent inverse relationship $(<-0.3)$ is found between COVID-19 and the daily Air Quality Index (AQI) from 1 Mar to 13 May 2021 (74 days). Thus, increase in temperature and winds, decrease in relative humidity were the climatic reasons, those chipped in COVID-19 cases surge and consequential enhancement of Air quality. These results are quite promising to comprehend the mutual tie-up between climate and COVID-19.
\end{abstract}

\section{Keywords}

Climate, Temperature, Humidity, Wind Speed, India, COVID-19

\section{Introduction}

The novel Coronavirus (COVID-19) disease caused by pathogenic agent SARS- 
COV-2 (severe acute respiratory syndrome coronavirus2), which was reported from Wuhan, China in December 2019 [1], proved to be highly contagious and took most of the countries of the world in its hold. The outbreak of novel coronavirus (2019-nCoV) was declared a Public Health Emergency of International Concern (PHEIC) by the World Health Organization (WHO) on 30 Jan 2020 and later on 11 March, 2020, it was declared as a pandemic by WHO concerning the alarming levels of spread and severity [2]. In India, the first case of COVID-19 was reported from the state of Kerala towards the end of Jan 2020 [3]. To contain the spread of the disease, the Indian government imposed a nationwide lockdown that continued from 25 Mar till 3 May, 2020. But despite adequate measures taken by the government in the very beginning to contain the spread of the pandemic, the COVID-19 cases continued rising primarily due to the highly contagious nature of the disease and due to breaches in the social distancing and mask-wearing norms. With continuous rising in the COVID-19 cases, India faced a peak in daily active COVID-19 cases with around 90000 daily new cases in midSeptember 2020, which dropped below 15,000 in January 2021. But from the first week of March 2021, cases in India once again started rising sharply, reaching around 392,000 daily new cases and around 4000 daily deaths in the first week of May 2021. The second wave of COVID-19 turned out to be even worse than the first wave, with reporting of around 100,000 deaths from 1 April, 2021 to 15 May 2021. The surge in the cases in the second wave in some states shows a correlation with the rise in the presence of double mutant B.1.617of SARS-CoV-2 [4]. Till 28 May 2021 total 27,555,457 confirmed cases and 318,895 deaths due to COVID-19 had been reported by India [5].

The uneven spread rate of the pandemic and difference in the fatality rate in the different regions of the world prompted many researchers from different parts of the world to investigate if there is any association of climatic variables with the spread of the disease and its fatality rate. Some studies suggested reduced activity of the virus in hot and humid conditions as found for SARS and other influenza also [6] [7] [8] [9]. On the basis of comparison of climate data for eight cities that are more affected with COVID-19 with 42 cities of the world for the period of January to 10 Mar 2020, [10] also reported the distribution of substantial community outbreaks of COVID-19 along restricted latitude, temperature, and humidity measurements and found it to be in line with the behavior of other seasonal respiratory viruses. A negative correlation between COVID-19 transmission and temperature was also reported in China [11]. A negative correlation between temperature and COVID-19 cases has been reported in several other regions, too, for instance, over Brazil by [12] and for Turkey by [13].

However, several researchers also reported on positive correlation of temperature with COVID-19 cases in different regions [14] for New York; [15] for Indonesia; [16] for India, [17] for Delhi; [18] for three Indian cities, and a positive correlation with humidity [16] [19]. [20] found a positive association between the mean temperature of the last two weeks and newly confirmed COVID-19 cases 
based on data of 122 cities of China. [21] suggested that local weather conditions with low temperature, mild diurnal temperature range, and low humidity likely favor transmission. [22] found no evidence of reduction in COVID-19 cases at warmer mean, minimum and maximum temperatures in a study over Spain. [23] suggested a strong association between higher average temperature and lower COVID-19 incidences.

Air pollution has also been found to be associated with the spread of COVID-19 by several researchers [24]. [24] found the significant role of particulate matter (PM) in the spread of COVID-19 in Italy. [25] reported positive relationships between air pollutant concentrations, specifically $\mathrm{NO}_{2}$ with COVID-19 mortality and infectivity in England and found PM2.5 a significant contributor to COVID-19 cases. In China also, a positive correlation of the Air Quality Index (AQI) is reported with COVID-19 cases [1]. A negative correlation of the lower environmental quality with the human immune system was suggested in China [26]. Though, in Germany, a significant relationship of the environmental quality index is found only with the active cases from COVID-19 pandemic [27].

Till now, relatively few studies have been reported analyzing the effect of weather conditions and air pollution on COVID-19 in different Indian states, although there is a significant difference between the weather conditions and air pollution over the other states of India. The difference in the correlation trends of meteorological parameters with COVID-19 over different regions prompted us to undertake this study over five states of India. This study provides a comparative analysis of the link between climatic variables and air pollution with COVID-19 and further enhances our understanding of climatic variables' impact on the spread of pandemics.

\section{Research Methodology}

The present study is done from 3 Jan to 15 May 2021 to explore the effect of the climate parameters on the COVID-19 cases. This period includes the second wave of COVID-19 in India and the Indian subcontinent, in which the double mutant B.1.617 of SARS-CoV-2 is supposed to be dominant in several states of India. For this period, the correlation of the climatic variables with the COVID-19 total confirmed cases, daily cases and fatalities is tested using non-parametric Kendall and Spearman rank correlation tests because the data was not found to be normally distributed. Spearman's rank correlation coefficient and Kendall's rank correlation coefficient are non-linear rank-based correlation coefficients that are frequently used to test the association between two variables. All the correlations are tested at $95 \%$ significance, otherwise stated at the bottom of each table. Results on Chandigarh were analyzed (not shown) on 99\% significance and interestingly there was hardly a change in the correlation coefficient values. The correlation test between AQI and COVID cases is done for the period of around two and half months, i.e., 1 Mar-May 13, 2021 (44 days). We tried Leg-lead correlation between COVID-19 and climatic variables, and the 7-days running mean of COVID-19 case data with climatic variables did not enhance the 
correlation coefficient than we showed in the present research work.

\subsection{Study Area}

Five Indian states/union territories are selected for the present study, i.e., Andhra Pradesh, Chandigarh, Delhi, Kerala and Puducherry. The reasons for the selection of these areas for the study are as follows:

1) There is a difference in temperature and humidity of the above states, so it provides the different climatic conditions (Figure 1) for exploring the link with COVID-19.

2) These states differ in respect to the air quality index (see Table 1). Out of the above, Puducherry remains least polluted while Delhi remains among India's most polluted regions. Therefore, to relatively analyze the effect of pollution on the fatality rate of Covid-19, the above states with different AQI records are chosen.

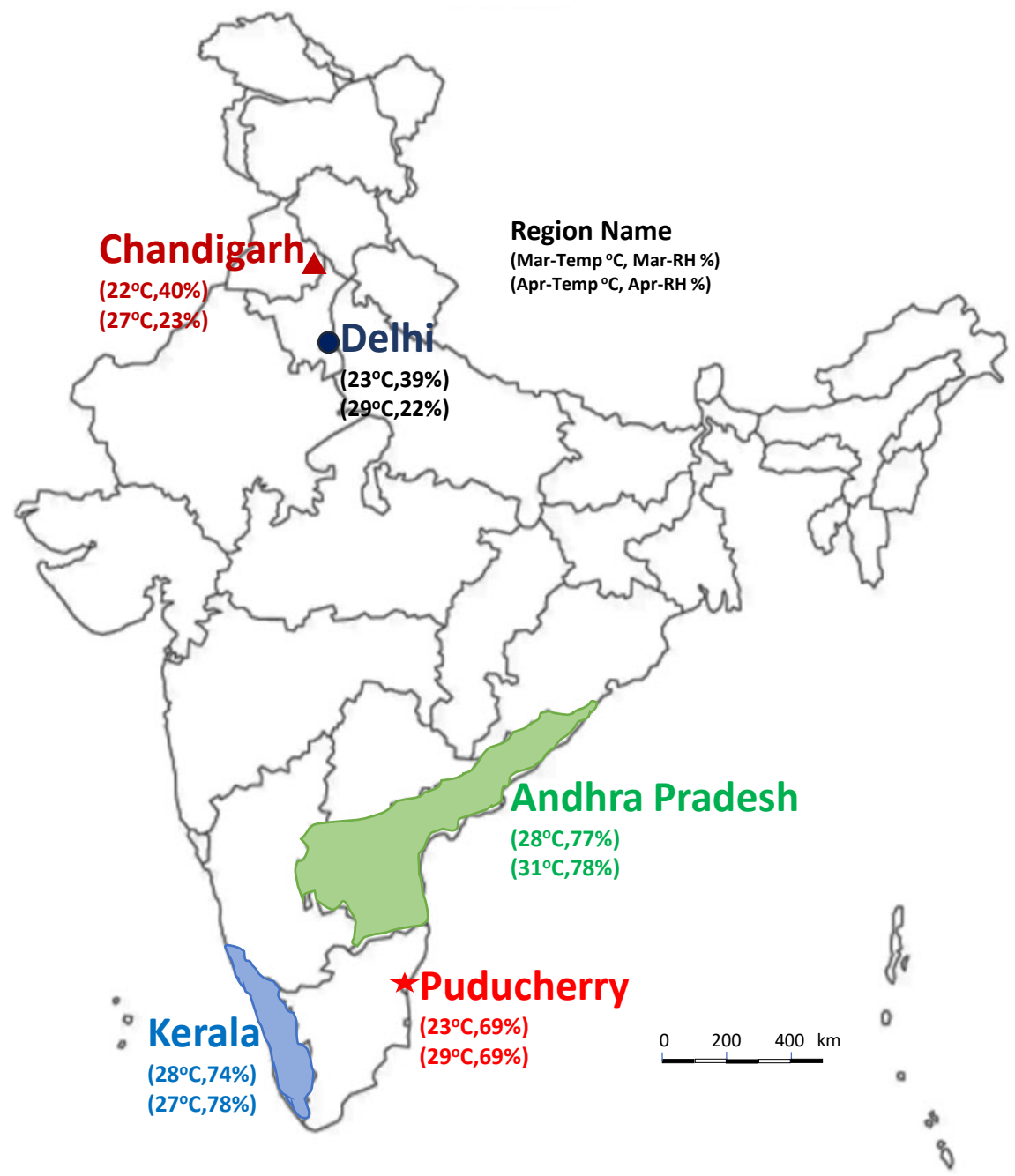

Figure 1. Display of 5-selected states/territories (Andhra Pradesh, Puducherry, Chandigarh, Delhi, Kerala) of India. In Bracket shows the climatic temperature $\left({ }^{\circ} \mathrm{C}\right)$ and relative humidity (\%) for March and April, respectively. 
Table 1. Details of population, area, decadal growth rate, population density and average AQI (for March and April) for the states/territories and total COVID-19 infected cases, deaths and case fatality rate as of 15 May 2021.

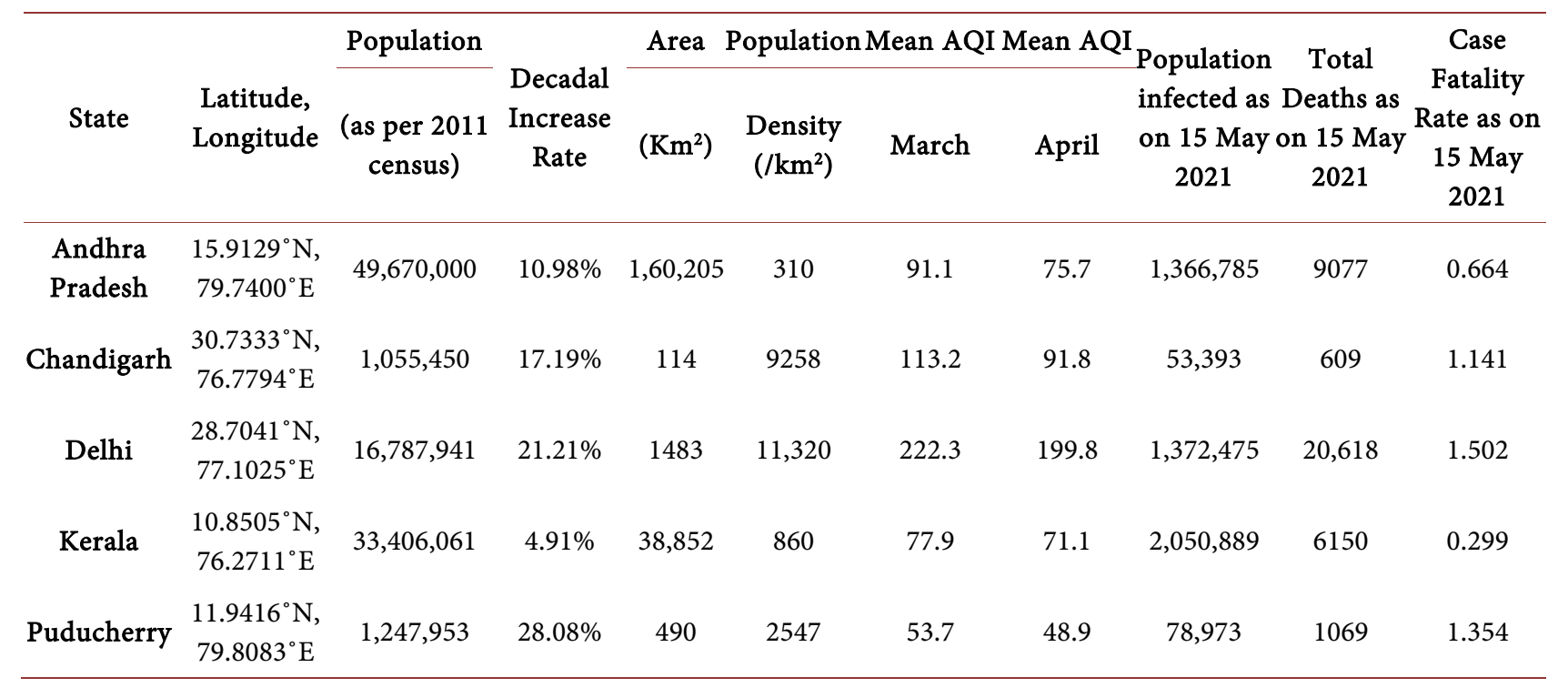

The population, area, population density, and mean AQI (over March and April) of the above states and territories are listed in Table 1. Among these, the total population of Andhra Pradesh is the highest, around 49.67 Million as per the 2011 census, but its population density is only 310 per sq. $\mathrm{km}$, which is the minimum among the states selected for the study. Out of these, Delhi has a maximum population density, i.e., 11,320 per sq. $\mathrm{km}$, and the highest case fatality rate of $1.50 \%$ (as of 15 May 2021), while in Kerala, the case fatality rate is the lowest $0.299 \%$ (as on 15 May 2021). Puducherry is the least polluted out of all the above states and territories, but the case fatality rate in Puducherry is $1.354 \%$ as of 15 May 2021.

\subsection{Data Collection}

For the above five regions, daily data for climate parameters like mean temperature $\left({ }^{\circ} \mathrm{C}\right)$, relative humidity $(\%)$ and wind speed $(\mathrm{m} / \mathrm{s})$ at $2 \mathrm{~m}$ height are taken from NASA Power Data Access Viewer [28]. For analyzing the effect of air pollution, the daily air quality index (AQI) for 1 Mar-13 May 2021 is retrieved from the Central Pollution Control Board website, India [29]. On this source, daily data of national air quality index values recorded at the different AQI stations of India are openly accessible. AQI data includes seven pollutants, e.g., PM2.5, PM10 and gases. On a particular day, the AQI is based on a prominent pollutant over a region.

For this study, the data for COVID-19 cases (total confirmed cases, total deaths and daily new cases) of Andhra Pradesh, Chandigarh, Delhi, Kerala and Puducherry is procured from [30] for the period 3 Jan-15 May 2021. This openly accessible source provides detailed information of COVID-19 cases of India statewide w.e.f. Mar 2020 as on 15 May 2021. 


\section{Results and Discussions}

\subsection{Contribution of Mean Temperature}

During COVID-19, a general belief was quite prevalent in the community that people living in hotter regions are less prone to virus infection. The same was believed that if the temperature rises, COVID-19 may go away [31]. Figure 1 shows the average temperature 3 Jan 2021 to 15 May 2021 for the five states/territories along with daywise COVID-19 total confirmed cases, total deaths and new cases. The estimated Kendall rank correlation coefficient values for average temperature and COVID-19 (total confirmed cases, total deaths and daily new cases) are given in Table 2. The correlation between temperature and COVID-19 remains relatively high $>0.6$ except over Kerala. Temperature over Kerala does not vary except $24^{\circ} \mathrm{C}$ to $30^{\circ} \mathrm{C}$ as compared to other states.

For all the states/territories in the period of study, a significant positive correlation between mean temperature and the COVID-19 confirmed cases are found (Table 2), which is in agreement with the recent studies done in the Indian context [16] [17] [18]. A positive correlation of temperature with COVID-19 total cases has been reported by several other researchers also, for instance, for New York [14] and Jakarta, Indonesia [15]. [20] found that the mean temperature of the last two weeks was positively associated with newly confirmed COVID-19 cases on the basis of a study over 122 cities from China, while a negative correlation of COVID-19 transmission and temperature was reported for China [11]. A negative correlation between temperature and COVID-19 cases has been reported for several other regions, for Brazil [12] and Turkey [13].

For all 5-India regions, the Kendall correlation coefficient for mean temperature and total deaths due to COVID-19 is positive (Table 2), which agrees with previous studies (Singh et al., 2020; Bashir et al., 2020). The degree of correlation is found to be similar to that found for confirmed cases. [17] found a strong positive relationship of mean, maximum and minimum temperature with the count of COVID-19 pandemic confirmed cases and deaths. [14] also reported a positive correlation of temperature with COVID-19 deaths for New York. A positive correlation of temperature with mortality rate was obtained [6] in China. [32] found an inverse correlation between COVID-19 deaths per million people and

Table 2. Kendall Correlation Coefficient for Mean Temperature $\left({ }^{\circ} \mathrm{C}, 2 \mathrm{~m}\right.$ height $)$ and COVID-19 total confirmed cases, deaths and daily new cases during 132 days period from 3 Jan-15 May 2021 with 95\% confidence interval.

\begin{tabular}{ccccc}
\hline & State/Territory & \multicolumn{3}{c}{ COVID-19 Cases } \\
\cline { 3 - 5 } & & Total Confirmed Cases & Total Deaths & Daily New Cases \\
\cline { 2 - 4 } Kendall Correlation coefficient & Andhra Pradesh & 0.745 & 0.744 & 0.556 \\
for Mean Temperature and & Chandigarh & 0.763 & 0.765 & 0.660 \\
COVID-19 cases & Delhi & 0.808 & 0.808 & 0.564 \\
& Kerala & 0.441 & 0.441 & $-0.142^{\star}$ \\
& Puducherry & 0.674 & 0.676 & 0.567 \\
\hline
\end{tabular}

${ }^{\star}$ Association not significat, $\mathrm{p}$-value $(2$-sided $)=0.018$. 
average monthly high temperatures considering the data of twenty-five areas located in Europe and the United States for the month of April 2020 (Figure 2).

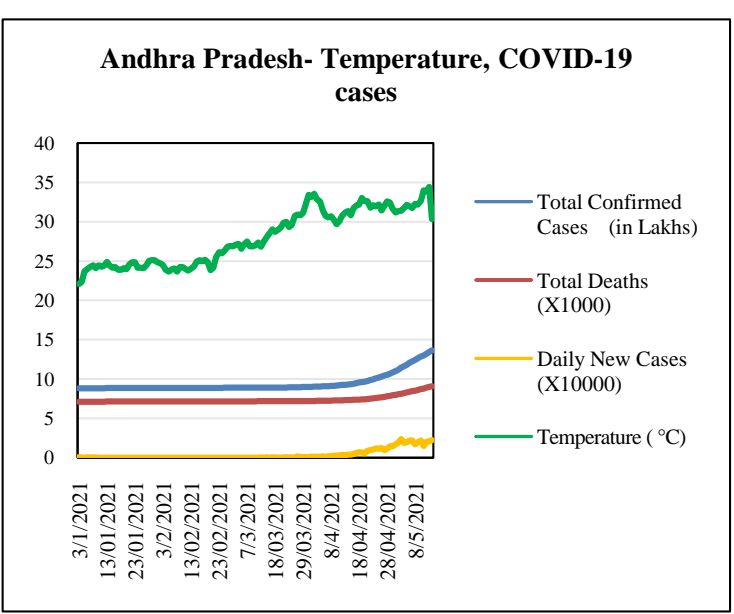

(a)

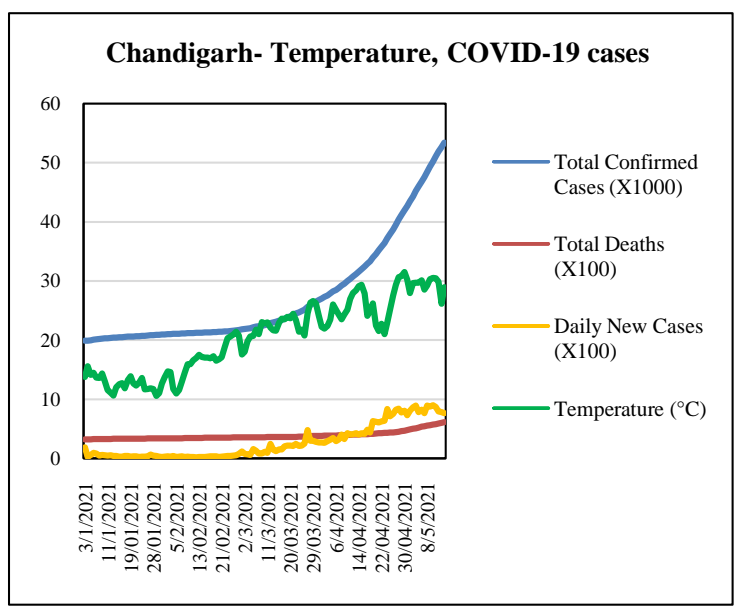

(c)

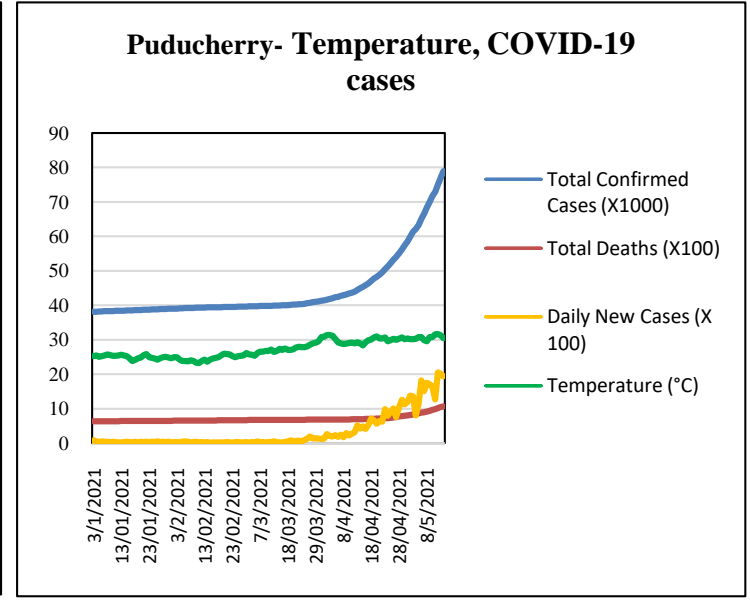

(b)

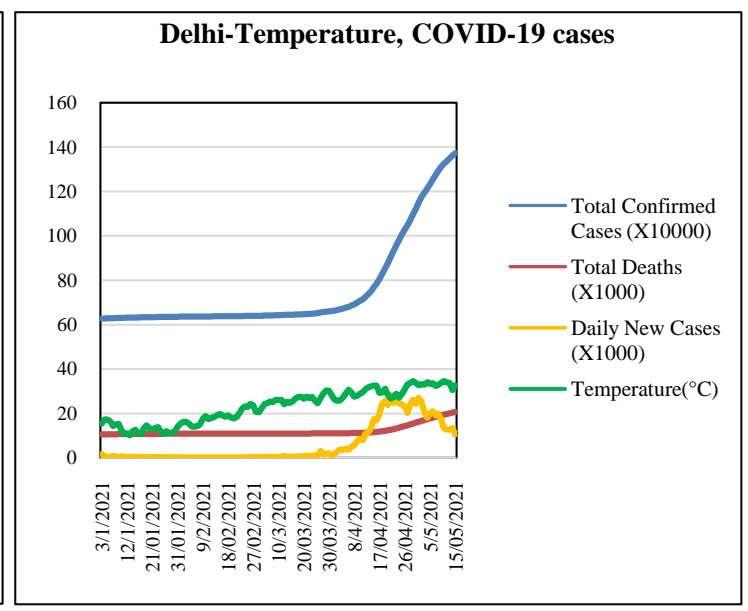

(d)

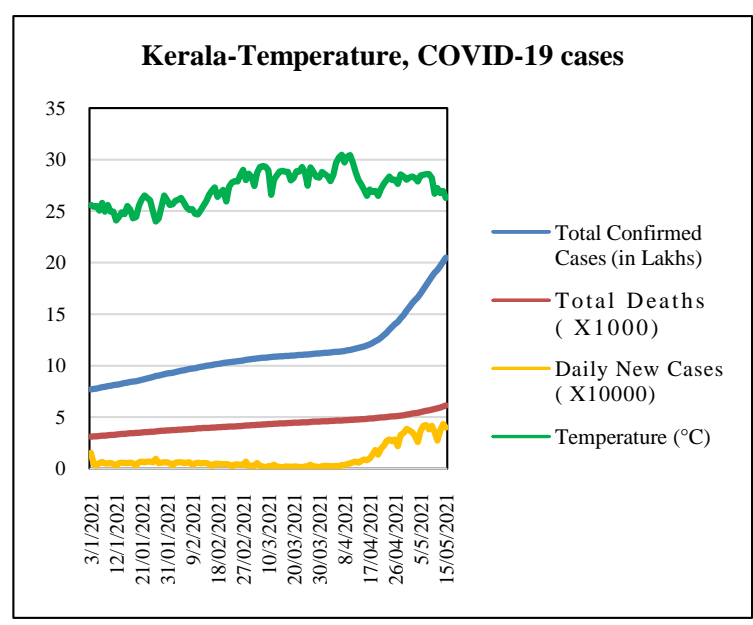

(e)

Figure 2. Daily variation of COVID-19 total confirmed cases, deaths, daily new cases, and temperature $\left({ }^{\circ} \mathrm{C}\right)$ from $1 \mathrm{Mar}$ to 15 May 2021, over (a) Andhra Pradesh, (b) Puducherry, (c) Chandigarh, (d) Delhi, (e) Kerala, states/territories of India. 
The mean temperature and daily new cases of COVID-19 are also found to have a positive correlation for all the states/territories except for Kerala, where the Kendall correlation coefficient for temperature and daily new cases is found to be negative with a 2-sided p-value of 0.018 (Table 2).

\subsection{Role of Moisture}

Humidity is another relevant factor that helps in fighting against viruses and infection. In general, the virus dies faster in the higher humidity; close to $60 \%$, relative humidity is optimum for that. Figure 2 shows the variation of relative humidity against days beginning from 3 Jan to 15 May 2021 for the five states/territories along with daywise COVID-19. There are large variations, and the humidity decreases overtime except for Kerala, which remains almost the same. However, in the last 30 days or so, the covid cases have increased drastically (Figure 2). The estimated values of the Kendall rank correlation coefficient for relative humidity and COVID-19 are displayed in Table 3. In most of the cases, the correlation remains negative $(<-0.4)$ except over Kerala.

It is found that there is an inverse relation of humidity with the total confirmed cases, deaths and daily new cases for all the regions taken for study except for Kerala, where no significant correlation is found (Table 3). The negative correlation of humidity with COVID-19 confirmed cases is in agreement with Gupta et al. (2020), who found that the transmission rate is likely inferior in the provinces under very wet and highly wet categories of climatic conditions. Wang et al. (2020) also found statistically significant negative correlations between temperature/relative humidity and COVID-19 transmission. However, Singh et al. (2020) found a positive correlation between confirmed cases and moisture on the basis of a study over 60 day period March 14-June 11, 2020, over NCT of Delhi, India (Figure 3).

Table 3. Kendall Correlation Coefficient for Relative Humidity (at $2 \mathrm{~m}$ height) and COVID-19 total confirmed cases, deaths and daily new cases during 132 days period from 3 Jan-15 May 2021 with 95\% confidence interval.

\begin{tabular}{ccccc}
\hline & & \multicolumn{3}{c}{ COVID-19 Cases } \\
\cline { 2 - 5 } & State/Territory & $\begin{array}{c}\text { Total Confirmed } \\
\text { Cases }\end{array}$ & $\begin{array}{c}\text { Total } \\
\text { Deaths }\end{array}$ & $\begin{array}{c}\text { Daily New } \\
\text { Cases }\end{array}$ \\
\cline { 2 - 5 } $\begin{array}{c}\text { Kendall Correlation } \\
\text { coefficient for Relative }\end{array}$ & Andhra & -0.516 & -0.515 & -0.231 \\
Humidity and & Pradesh & -0.466 & -0.469 & -0.397 \\
COVID-19 cases & Delhi & -0.603 & -0.603 & -0.372 \\
& Kerala & $0.105^{*}$ & $0.105^{*}$ & 0.381 \\
& Puducherry & -0.595 & -0.597 & -0.382 \\
\hline
\end{tabular}

${ }^{*}$ Association not significant, $\mathrm{p}$-value $(2$-sided $)=0.08$. 


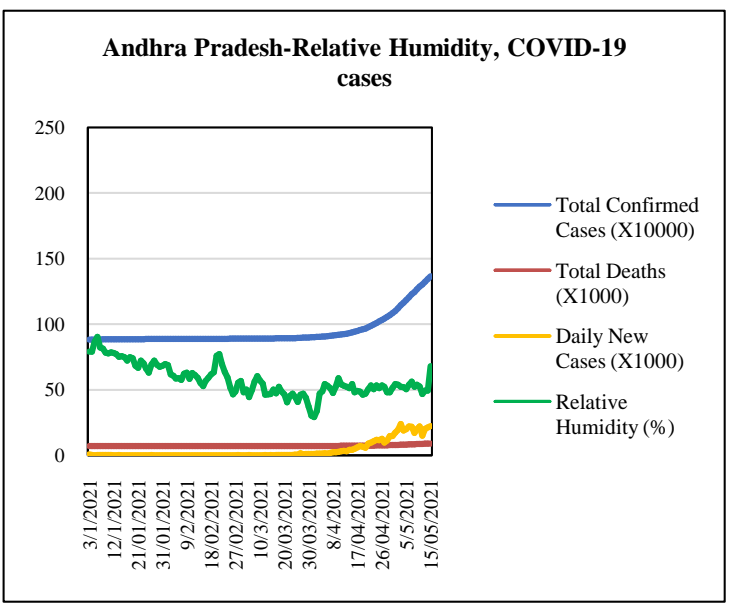

(a)

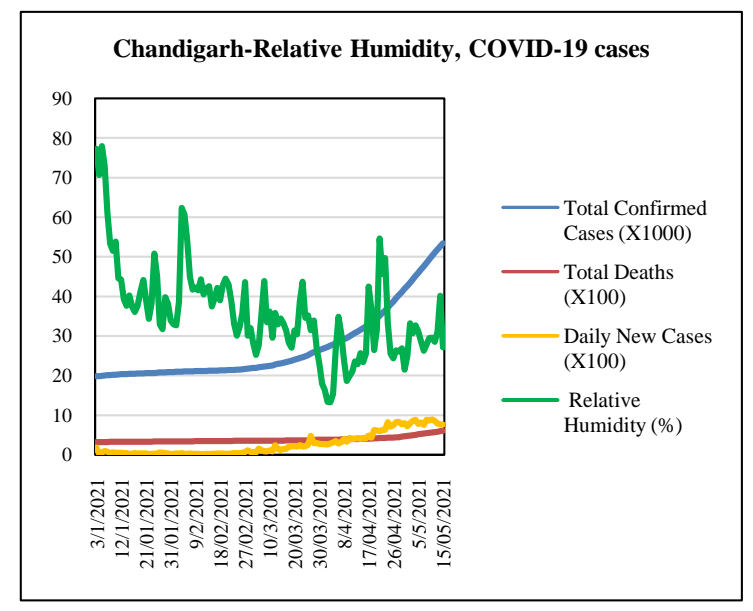

(c)
Puducherry- Relative Humidity, COVID-19 cases

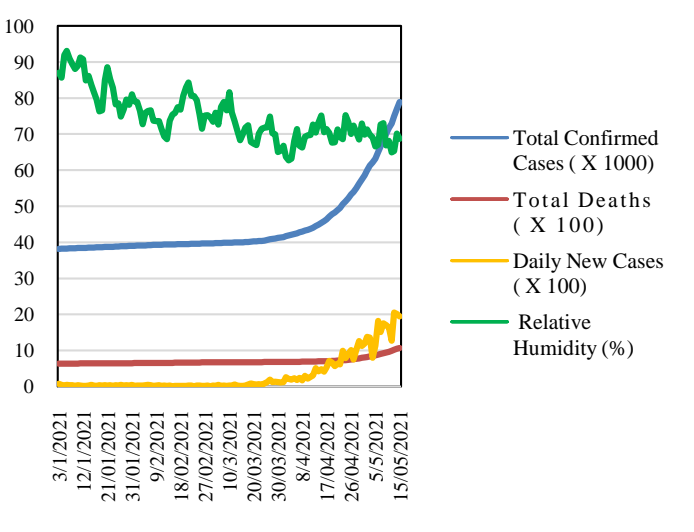

(b)

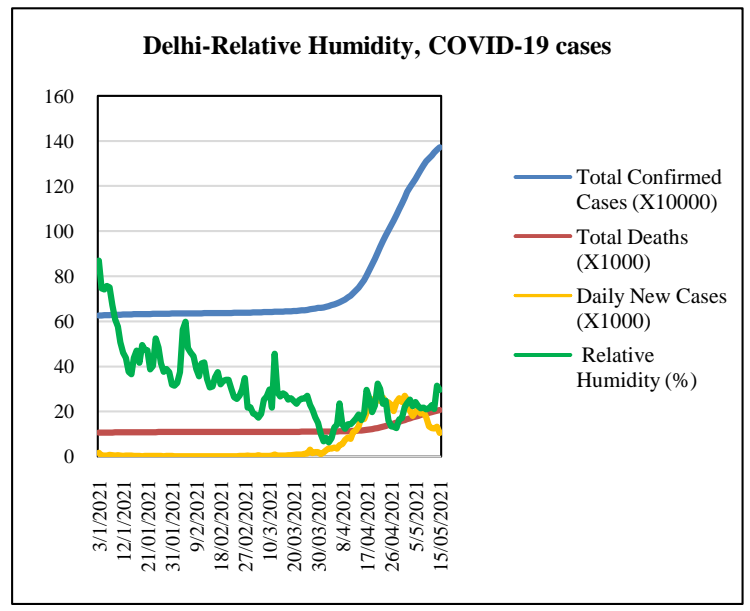

(d)

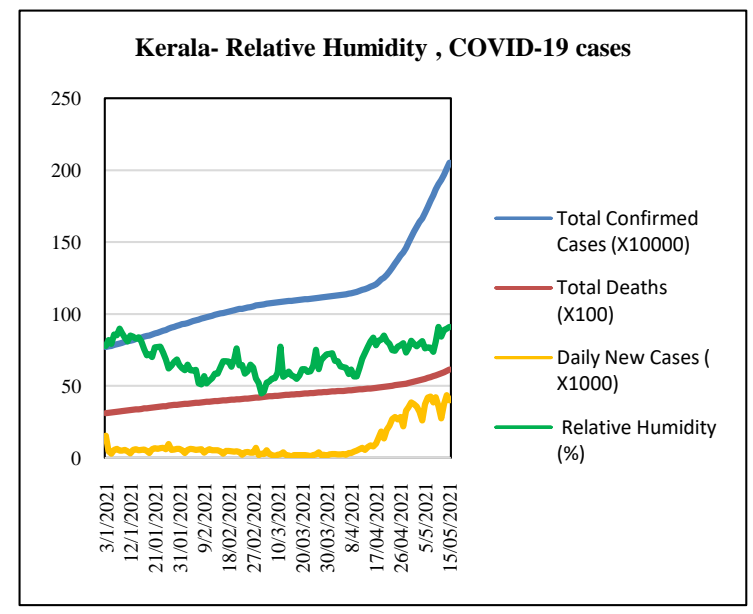

(e)

Figure 3. Daily variation of COVID-19 total confirmed cases, deaths, daily new cases and relative humidity (\%) from $1 \mathrm{Mar}$ to 15 May 2021, over (a) Andhra Pradesh, (b) Puducherry, (c) Chandigarh, (d) Delhi, (e) Kerala, states/territories of India.

\subsection{Wind Factor}

A safe distance of 6-feet was recommended from the WHO so that the spread 
of the virus was restricted further due to the limited nature of the airborne COVID-19 virus. A positive correlation is found of wind speed with COVID-19 cases for Andhra Pradesh and Chandigarh, while for Kerala and Puducherry, the correlation with COVID-19 is found to be negative (Table 4). In Andhra Pradesh, the degree of wind speed correlation is higher than in other regions because of the increase in the wind in the latter period. In Delhi, no significant correlation of confirmed cases and deaths with wind speed is found, while a weak positive correlation is found with daily new cases of COVID-19. Before June, the wind pattern over Delhi remains pretty chaotic; a regular wind pattern forms from mid of June. Singh et al. (2020) have found a weak correlation of wind speed with COVID-19 confirmed and deceased cases for Delhi, while Sahin (2020) showed a negative correlation with the wind speed on the day in Turkey (Figure 4).

Table 4. Kendall Correlation Coefficient for Wind Speed (at $2 \mathrm{~m}$ height) and COVID-19 total confirmed cases, deaths and daily new cases during 132 days period from January 3 , 2021-May 15, 2021 with 95\% confidence interval.

\begin{tabular}{ccccc}
\hline & State/Territory & \multicolumn{3}{c}{ COVID-19 Cases } \\
\cline { 3 - 5 } & $\begin{array}{c}\text { Total Confirmed } \\
\text { Cases }\end{array}$ & $\begin{array}{c}\text { Total } \\
\text { Deaths }\end{array}$ & $\begin{array}{c}\text { Daily New } \\
\text { Cases }\end{array}$ \\
\cline { 2 - 5 } $\begin{array}{c}\text { Kendall Correlation } \\
\text { coefficient for Wind } \\
\text { Speed and }\end{array}$ & $\begin{array}{c}\text { Andhra } \\
\text { Pradesh }\end{array}$ & 0.513 & 0.514 & 0.461 \\
COVID-19 cases & Chandigarh & 0.233 & 0.230 & 0.243 \\
& Delhi & $0.103^{* 1}$ & $0.103^{* 2}$ & 0.199 \\
& Kerala & -0.242 & -0.242 & $-0.062^{* 3}$ \\
& Puducherry & -0.176 & -0.177 & $-0.040^{* 4}$ \\
\hline
\end{tabular}

${ }^{\star} 1$-association not significant, $\mathrm{p}$-value $(2$-sided $)=0.08,{ }^{\star} 2$-association not significant, $\mathrm{p}$-value $(2$-sided $)=0.086,{ }^{\star} 3$-association not significant, $\mathrm{p}$-value $(2$-sided $)=0.30,{ }^{\star} 4$ association not significant, $\mathrm{p}$-value $(2$-sided $)=0.51$.

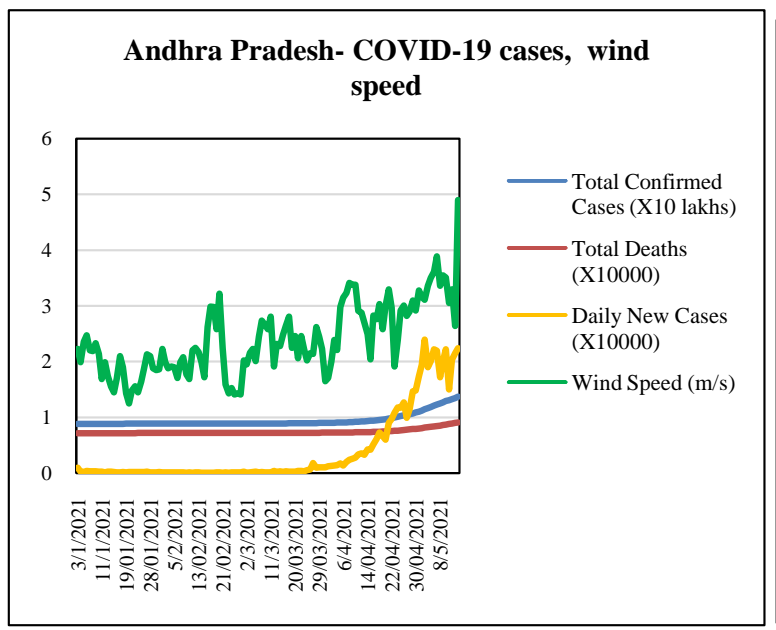

(a)
Puducherry-COVID-19 cases, wind speed

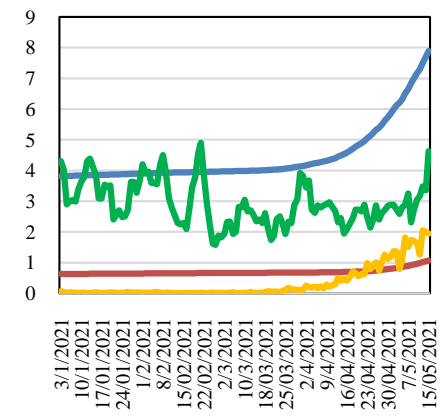

(b) 


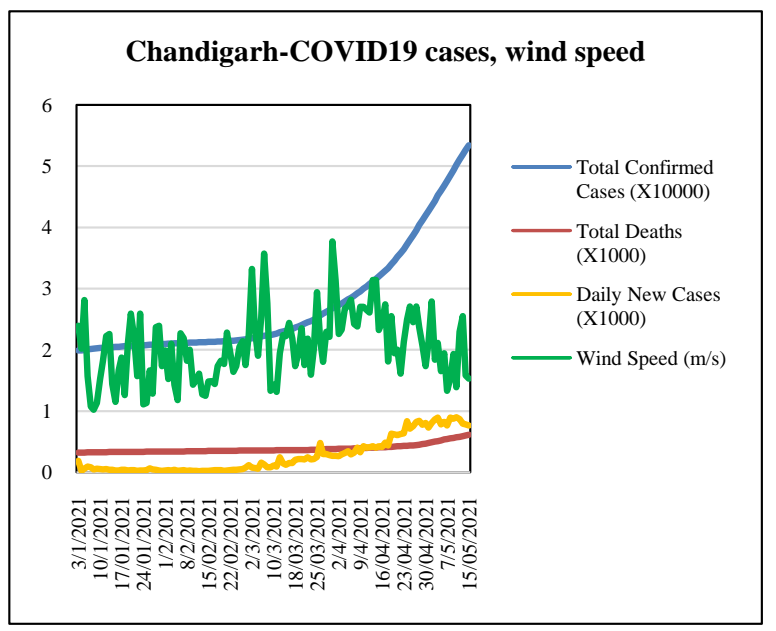

(c)

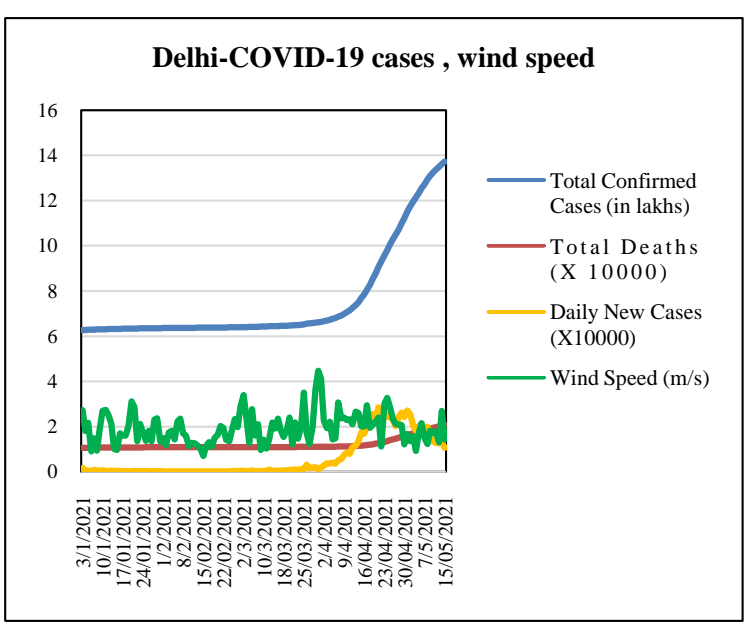

(d)

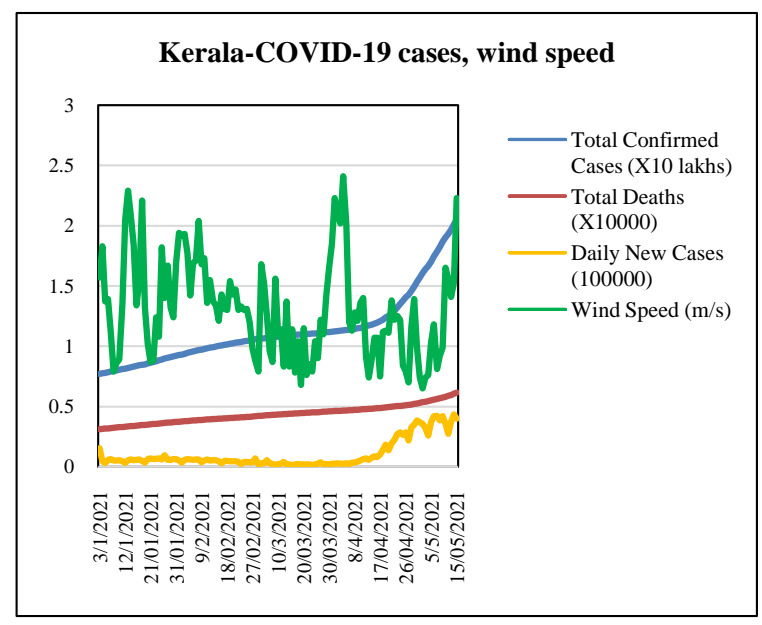

(e)

Figure 4. Daily variation of COVID-19 total confirmed cases, deaths, daily new cases and wind speed ( $\mathrm{m} / \mathrm{s})$ from 1 March to 15 May 2021, over (a) Andhra Pradesh, (b) Puducherry, (c) Chandigarh, (d) Delhi, (e) Kerala, states/territories of India.

The droplet pruced during cough, sneeze and talk by a COVID-19 patient may acrried away by wind for a particular distance. On drying the dropmet the COVID-19 virus may hand in the air for minutes to hours.

Supplementary tables (S1-S3) provide the value of Spearman's rank correlation coefficient for three Climate variables (average temperature, humidity and wind speed) and COVID-19 cases (total confirmed cases, total deaths and daily new cases). It is observed that the Spearman rank correlation test also comes out with a similar correlation in magnitude and sign but slightly higher as compared to the Kendall rank correlation test.

\subsection{Consequence of COVID-19 on Air Quality}

Before the monsoon season (June to September), the quality of the air remains quite fluctuating over the Indian region. Figure 5 shows the daywise variation of AQI for the states along with COVID-19 cases from 1 Mar to 15 May 2021. Some of the low and high peaks in AQI are quite visible over five regions. 


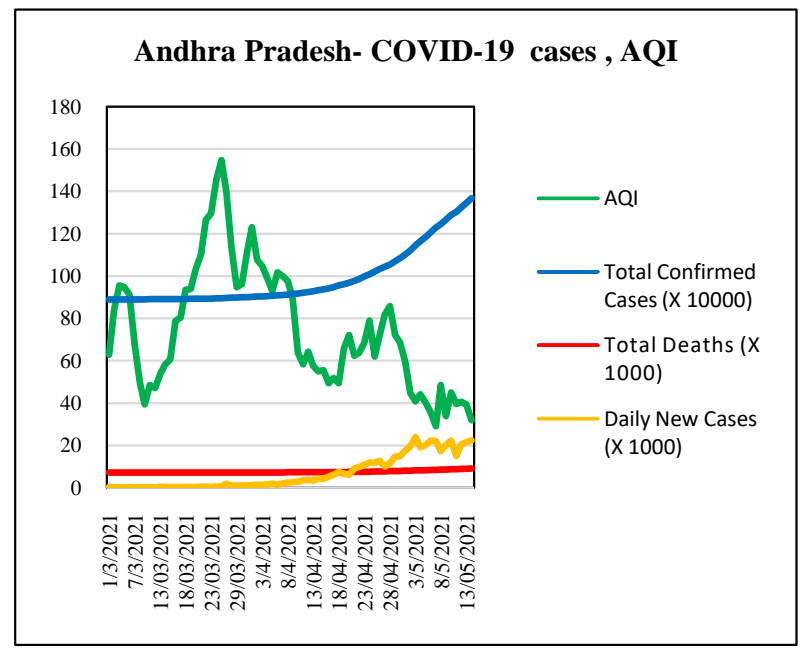

(a)

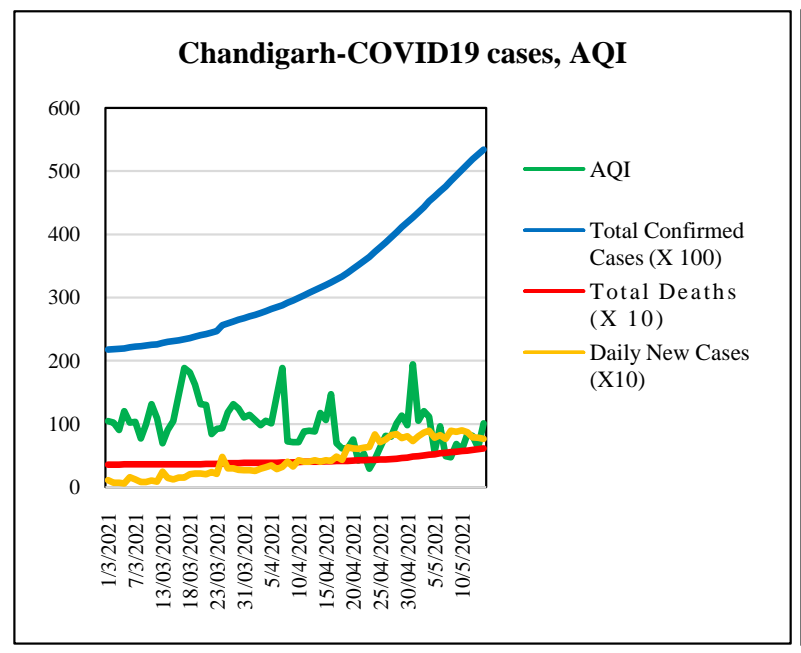

(c)

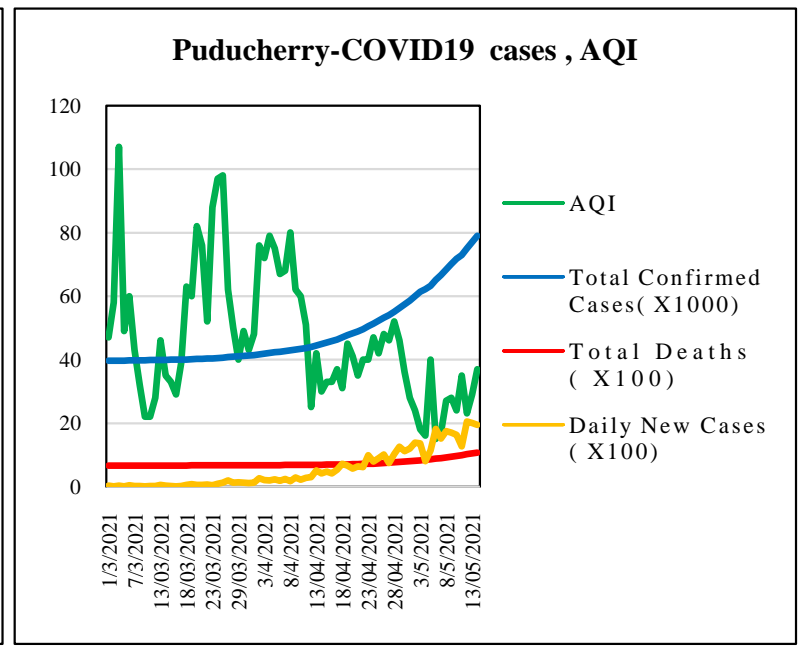

(b)

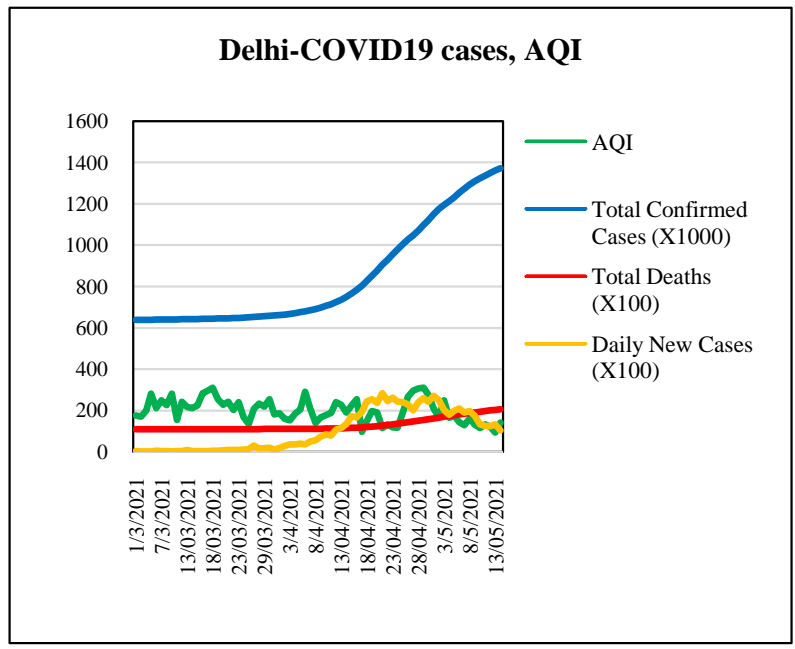

(d)

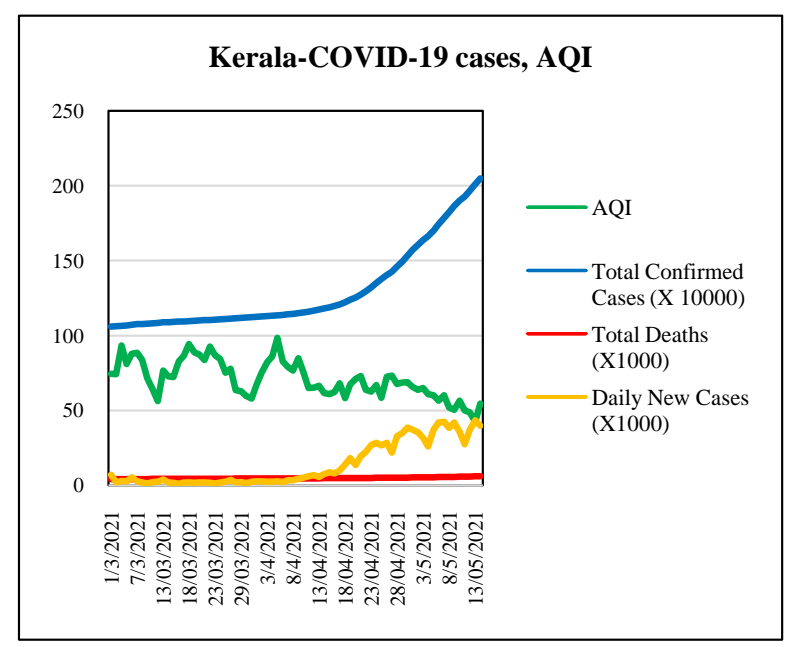

(e)

Figure 5. Daily variation of AQI for the states/territories along with the COVID-19 total confirmed cases, deaths and daily new cases for the duration 1 Mar to 13 May 2021 over (a) Andhra Pradesh, (b) Puducherry, (c) Chandigarh, (d) Delhi, (e) Kerala, states/territories of India. 
Table 5 lists the Kendall rank correlation coefficient for air quality index (AQI) and COVID-19 for all the regions from 1 Mar to 13 May 2021. Overall a negative association is observed between the AQI and COVID-19 total confirmed cases, total deaths and daily new cases for all the states/territories. Similar results are obtained with the Spearman rank correlation test (Table 5). These results are not consistent with [24] [25], where positive relationships were reported between air pollutant concentrations and COVID-19 infectivity for England and Italy, respectively. A positive correlation of AQI is reported based on the data of 120 cities of China for the duration 23 Jan to 29 Feb 2020 [1]. Chinese provincial data suggested a negative correlation of the lower environmental quality with the human immune system (Han et al., 2020). Though in Germany, it was found that the environmental quality index has a significant relationship only with the active cases from COVID-19 pandemic (Bilal et al., 2020). The disparity in the trends of correlation of COVID cases with AQI obtained in the present work possibly indicates that other factors may too dominate the association with AQI. Wherever the covid cases were rising, there were a few top reasons for the increase in AQI, e.g., deployment of lockdown, work from home, shutting down of many small and medium industries. Many of the leading newspapers covered the fact of clearly visible Himalayan peaks from Chandigarh. Improve in AQI will undoubtedly lessen the risk from COVID-19 illness, especially in preexisting respiratory conditions public.

Overall, as per the present study, a positive correlation with temperature and a negative correlation with humidity are found (except Kerala). However, the different trends of association of meteorological parameters with COVID-19 cases reported from different parts of the world indicate that the effect of other factors like proper prevention policies and strict implementation of these policies is far more on the spread of the disease as compared to the meteorological factors. The present study's limitation is with the use of the short duration (data from the single peak of COVID case) of datasets, limited statistical methods, and other related factors that might have aided in the surge of covid-19 cases. There was a reduction of aerosol loading (aerosol optical depth) over the Indo-Gangetic plain by $35 \%$ during the COVID time [33]. April 2021 lockdown reduced industrial, business, and energy consumption were few significant sectors responsible for cair quality enhancement.

Table 5. Kendall correlation coefficient Air Quality Index (AQI) andCOVID-19 total confirmed cases, deaths and daily new cases during 74 days period from 1 Mar-13 May 2021 with $95 \%$ confidence interval.

\begin{tabular}{cccc}
\hline \multirow{2}{*}{ State/Territory } & $\begin{array}{c}\text { Kendall Correlation Coefficient- } \\
\text { AQI and Total Confirmed Cases }\end{array}$ & $\begin{array}{c}\text { Kendall Correlation Coefficient- Kendall Correlation Coefficient- } \\
\text { AQI and Total Deaths }\end{array}$ & \begin{tabular}{c} 
AQI and Daily New Cases \\
\hline Andhra Pradesh
\end{tabular} \\
Chandigarh & -0.370 & -0.373 & -0.379 \\
Delhi & -0.284 & -0.284 & -0.305 \\
Kerala & -0.286 & -0.286 & -0.235 \\
Puducherry & -0.497 & -0.497 & -0.453 \\
\hline
\end{tabular}




\section{Conclusions}

An association between COVID-19 and climate variables is investigated during 3 Jan-15 May 15, 2021 (132 days), which includes April 2021, a month of a sharp rise in COVID-19, second wave. Five regions (Andhra Pradesh, Chandigarh, Delhi, Kerala and Puducherry) of distinguished climate and weather are selected for this study, where the Kendall rank correlation test and Spearman correlation are being calculated at $95 \%$ significance. We summarize the results as follows:

1) COVID-19 cases and the mean temperature have a decent association over five selected regions, Kendall rank correlation (up to 0.81) and Spearman correlation (0.95). COVID-19 cases rise with the rising temperature over Indian regions.

2) A negative correlation is obtained between COVID-19 and relative humidity cases. It shows that humidity also controls the spread of COVID-19 cases.

3) Winds can carry the air-borne particle over a specific distance. However, in the case of COVID-19, a weak link is found with wind speed except over Andhra Pradesh.

4) The presence of aerosol (PM2.5) in the air may aid in spreading COVID-19. However, over Indian regions, a negative correlation of Air Quality Index (AQI, 1 Mar to 13 May 2021) with COVID-19 cases shows a consequence of lockdown, an improvement in air quality.

The results presented here tried to find a monotonic link between COVID-19 cases and climatic conditions over selected regions. Further, we regard the inadequacy of the correlation test in relating the effect of temperature, humidity, wind speed, AQI on the transmission of the COVID-19 spread. The association between climate over a region is always being related to regional and local diseases. Thus, the notion of the impact of weather on disease and illness will always remain one of the research topics. How much one impacts others is a bit complex to separate their influences. The apparent interruption caused by COVID-19 brought several impressions on the environment, business, transportation, education and society. The positive impact was seen on greenhouse gases, and noise pollution. On ecology point of view water quality was improved, and few cases where forest animals were came out on roads and in residential areas. Air quality had been improved in many cities due to travel and social gatherings restrictions.

For better understanding, the authors suggest using suitable statistical methods (e.g., multiple regression analysis), including influences from many other variables. Such inclusion may help find a reliable and robust outcome. Long term impact of COVID-19 on air quality is still unknown. However, the way COVID-19 has changed the lifestyle towards online learning and working from home may have a greater impact on societal and environmental impacts. Further scope to this work may be testing this correlation further for longer and different periods incorporating effects of other factors like population density and prevention policies/measures. 


\section{Acknowledgements}

The authors are thankful for all the data sources from where data is procured. All the authors have read the manuscript and agreed on the contents. The authors are accountable for the accuracy and integrity of the manuscript. The submitted manuscript presents a new finding. It has not been submitted anywhere else than the Journal of Environmental Protection (JEP).

\section{Availability of Data and Material}

All the dataset used in the research is publicly available to everyone. The corresponding links of datasets are provided in the manuscript. The processed data and figure will be provided to one on request.

\section{Author's Contributions}

K.M. contributed with the conceptualization, methodology, data curation, formal analysis, investigation, and writing. At the same time, V.K did analysis, writing \&editing and formatting of the manuscript.

\section{Conflicts of Interest}

The authors declare no conflicts of interest regarding the publication of this paper.

\section{References}

[1] Zhu, Y., Xie, J., Huang, F. and Cao, L. (2020) Association between Short-Term Exposure to Air Pollution and COVID-19 Infection: Evidence from China. Science of the Total Environment, 727, Article ID: 138704.

https://doi.org/10.1016/j.scitotenv.2020.138704

[2] WHO (2020) COVID-19 Public Health Emergency of International Concern (PHEIC) Global Research and Innovation Forum: Towards a Research Roadmap. World Health Organization.

https://www.who.int/publications/m/item/covid-19-public-health-emergency-of-int ernational-concern-(pheic)-global-research-and-innovation-forum

[3] Andrews, M.A., Areekal, B., Rajesh, K.R., Krishnan, J., Suryakala, R., Krishnan, B., Muraly, C.P. and Santhosh, P.V. (2020) First Confirmed Case of COVID-19 Infection in India: A Case Report. Indian Journal of Medical Research, 151, 490-492.

[4] BBC News on COVID Surge in India. https://www.bbc.com/news/world-asia-india-57004764

[5] WHO on COVID Cases in India. https://covid19.who.int/region/searo/country/in

[6] Ma, Y., Zhao, Y., Liu, J., He, X., Wang, B., Fu, S., Yan, J., Niu, J., Zhou, J. and Luo, B. (2020) Effects of Temperature Variation and Humidity on the Death of COVID-19 in Wuhan, China. Science of the Total Environment, 724, Article ID: 138226. https://doi.org/10.1016/j.scitotenv.2020.138226

[7] Oliveiros, B., Caramelo, L., Ferreira, N.C. and Caramelo, F. (2020) Role of Temperature and Humidity in the Modulation of the Doubling Time of COVID-19 Cases. MedRxiv. https://doi.org/10.1101/2020.03.05.20031872

[8] Wang, J., Tang, K., Feng, K., Lin, X., Lv, W., Kun, C. and Wang, F. (2020) Impact of 
Temperature and Relative Humidity on the Transmission of COVID-19: A Modeling Study in China and the United States. BMJ Open, 11, e043863. https://doi.org/10.1136/bmjopen-2020-043863

[9] Vinoj, V., Gopinath, N., Landu, K., Behera, B. and Mishra, B. (2020) The COVID-19 Spread in India and Its Dependence on Temperature and Relative Humidity. https://doi.org/10.20944/preprints202007.0082.v1

[10] Sajadi, M.M., Habibzadeh, P., Vintzileos, A., Shokouhi, S., Miralles-Wilhelm, F. and Amoroso, A. (2020) Temperature, Humidity, and Latitude Analysis to Estimate Potential Spread and Seasonality of Coronavirus Disease 2019 (COVID-19). JAMA Network Open, 3, e2011834. https://doi.org/10.1001/jamanetworkopen.2020.11834

[11] Shi, P., Dong, Y., Yan, H., Zhao, C., Li, X., Liu, W., He, M., Tang, S. and Xi, S. (2020) Impact of Temperature on the Dynamics of the COVID-19 Outbreak in China. Science of the Total Environment, 728, Article ID: 138890.

https://doi.org/10.1016/j.scitotenv.2020.138890

[12] Prata, D.N., Rodrigues, W. and Bermejo, P.H. (2020) Temperature Significantly Changes COVID-19 Transmission in (Sub)Tropical Cities of Brazil. Science of the Total Environment, 729, Article ID: 138862.

https://doi.org/10.1016/j.scitotenv.2020.138862

[13] Şahin, M. (2020) Impact of Weather on COVID-19 Pandemic in Turkey. Science of the Total Environment, 728, Article ID: 138810. https://doi.org/10.1016/j.scitotenv.2020.138810

[14] Bashir, M.F., Ma, B., Bilal-Komal, B., Bashir, M.A., Tan, D. and Bashir, M. (2020) Correlation between Climate Indicators and COVID-19 Pandemic in New York, USA. Science of the Total Environment, 728, Article ID: 138835. https://doi.org/10.1016/j.scitotenv.2020.138835

[15] Tosepu, R., Gunawan, J., Effendy, D. S., Imran-Ahmad L.O.A, Lestari, H., Bahar, H., Asfian, P. (2020) Correlation between Weather and Covid-19 Pandemic in Jakarta, Indonesia. Science of the Total Environment, 725, Article ID: 138436. https://doi.org/10.1016/j.scitotenv.2020.138436

[16] Sharma, P., Singh, A.K., Agarwal, B. and Sharma, A. (2020) Correlation between Weather and COVID-19 Pandemic in India: An Empirical Investigation. Journal of Public Affairs, 20, e2222. https://doi.org/10.1002/pa.2222

[17] Singh, O., Bhardwaj, P. and Kumar, D. (2020) Association between Climatic Variables and COVID-19 Pandemic in National Capital Territory of Delhi, India. Environment, Development and Sustainability, 23, 9514-9528. https://doi.org/10.1007/s10668-020-01003-6

[18] Gupta, A., Banerjee, S. and Das, S. (2020) Significance of Geographical Factors to the COVID-19 Outbreak in India. Modeling Earth Systems and Environment, 6, 2645-2653. https://doi.org/10.1007/s40808-020-00838-2

[19] Bherwani, H., Gupta, A., Anjum, S., et al. (2020) Exploring Dependence of COVID-19 on Environmental Factors and Spread Prediction in India. NPJ Climate and Atmospheric Science, 3, Article No. 38. https://doi.org/10.1038/s41612-020-00142-x

[20] Xie, J. and Zhu, Y. (2020) Association between Ambient Temperature and COVID-19 Infection in 122 Cities from China. Science of the Total Environment, 724, Article ID: 138201. https://doi.org/10.1016/j.scitotenv.2020.138201

[21] Liu, J., et al. (2020) Impact of Meteorological Factors on the COVID-19 Transmission: A Multi-City Study in China. Science of the Total Environment, 726, Article ID: 138513. https://doi.org/10.1016/j.scitotenv.2020.138513

[22] Briz-Redón, Á. and Serrano-Aroca, Á. (2020) A Spatio-Temporal Analysis for Ex- 
ploring the Effect of Temperature on COVID-19 Early Evolution in Spain. Science of the Total Environment, 728, Article ID: 13811. https://doi.org/10.1016/j.scitotenv.2020.138811

[23] Bannister-Tyrrell, M., Meyer, A., Faverjon, C. and Cameron, C. (2020) Preliminary Evidence that Higher Temperatures Are Associated with Lower Incidence of COVID19, for Cases Reported Globally up to 29th February 2020. MedRxiv. https://doi.org/10.1101/2020.03.18.20036731

[24] Comunian, S., Dongo, D., Milani, C. and Palestini, P. (2020) Air Pollution and Covid-19: The Role of Particulate Matter in the Spread and Increase of Covid-19's Morbidity and Mortality. International Journal of Environment Research on Public Health, 17, Article No. 4487. https://doi.org/10.3390/ijerph17124487

[25] Travaglio, M., Yu, Y., Popovic, R., Selley, L., Leal, N.S. and Martins, L.M. (2021) Links between Air Pollution and COVID-19 in England. Environmental Pollution, 268, Article ID: 115859. https://doi.org/10.1016/j.envpol.2020.115859

[26] Han, Y., Lam, J., Li, V., Guo, P., Zhang, Q., Wang, A. Crowcroft, J., Wang, S., Fu, J. and Gilani, Z. (2020) The Effects of Outdoor Air Pollution Concentrations and Lockdowns on Covid-19 Infections in Wuhan and Other Provincial Capitals in China. https://doi.org/10.20944/preprints202003.0364.v1

[27] Bilal-Bashir, B.M.F., Benghoul, M., et al. (2020) Environmental Pollution and COVID19 Outbreak: Insights from Germany. Air Quality, Atmosphere \& Health, 13, 1385 1394. https://doi.org/10.1007/s11869-020-00893-9

[28] Power Data Access from NASA. https://power.larc.nasa.gov/data-access-viewer/

[29] National AQI. https://app.cpcbccr.com/AQI India/

[30] COVID Cases for Indian States. https://prsindia.org/covid-19/cases

[31] Chen, S., Prettner, K., Kuhn, M., et al. (2021) Climate and the Spread of COVID-19. Scientific Reports, 11, Article No. 9042. https://doi.org/10.1038/s41598-021-87692-Z

[32] Benedetti, F., Snyder, G.A., Giovanetti, M., et al. (2020) Emerging of a SARS-CoV-2 Viral Strain with a Deletion in nsp1. Journal of Translational Medicine, 18, Article No. 329. https://doi.org/10.1186/s12967-020-02507-5

[33] Bhawar, R.L., Fadnavis, S., Kumar, V., Rahul, P.R.C., Sinha, T. and Lolli, S. (2021) Radiative Impacts of Aerosols during COVID-19 Lockdown Period over the Indian Region. Frontier of Environmental Science, 9, Article ID: 746090. https://doi.org/10.3389/fenvs.2021.746090 